\title{
A Correlation between the Ultimate Shear Stress and the Thickness Affected by Intermetallic Compounds in Friction Stir Welding of Dissimilar Aluminum Alloy-Stainless Steel Joints
}

\author{
Florent Picot ${ }^{1,2}$, Antoine Gueydan ${ }^{1}$, Mayerling Martinez ${ }^{1}$, Florent Moisy ${ }^{1}$ and Eric Hug ${ }^{1, *}$ \\ 1 Laboratoire de Cristallographie et Sciences de Matériaux, Normandie Université, ENSICAEN, \\ CNRS UMR 6508, 6 Boulevard du Maréchal Juin, 14050 Caen, France; florent.picot@ensicaen.fr (F.P.); \\ antoine.gueydan@ensicaen.fr (A.G.); mayerling.martinez@ensicaen.fr (M.M.); \\ florent.moisy@ensicaen.fr (F.M.) \\ 2 Sominex, 13 rue de la Résistance, 14400 Bayeux, France \\ * Correspondence: eric.hug@ensicaen.fr; Tel.: +33-231-451-313
}

Received: 19 February 2018; Accepted: 9 March 2018; Published: 13 March 2018

\begin{abstract}
In this work, Friction Stir Welding (FSW) was applied to join a stainless steel 316L and an aluminum alloy 5083. Ranges of rotation and translation speeds of the tool were used to obtain welding samples with different heat input coefficients. Depending on the process parameters, the heat generated by FSW creates thin layers of Al-rich InterMetallic Compound (IMC) mainly composed of $\mathrm{FeAl}_{3}$, identified by energy dispersive spectrometry. Traces of $\mathrm{Fe}_{2} \mathrm{Al}_{5}$ were also depicted in some samples by X-ray diffraction analysis and transmission electron microscopy. Monotonous tensile tests performed on the weld joint show the existence of a maximum mechanical resistance for a judicious choice of rotation and translation speeds. It can be linked to an affected zone of average thickness of $15 \mu \mathrm{m}$ which encompass the presence of IMC and the chaotic mixing caused by plastic deformation in this area. A thickness of less than $15 \mu \mathrm{m}$ is not sufficient to ensure a good mechanical resistance of the joint. For a thickness higher than $15 \mu \mathrm{m}$, IMC layers become more brittle and less adhesive due to high residual stresses which induces numerous cracks after cooling. This leads to a progressive decrease of the ultimate shear stress supported by the bond.
\end{abstract}

Keywords: FSW process; aluminum alloy; stainless steel; intermetallic compounds; mechanical strength

\section{Introduction}

Unlike traditional welding methods, Friction Stir Welding (FSW) is an assembly technique which occurs without additional metal and does not reach the melting point of the materials [1]. Numerous fields of application can find advantages of the process such as automotive and railway industries [2]. Critical technological fields such as air transport, the development of fuel tanks for aerospace applications and the nuclear industry also use FSW to join alloys [3]. The FSW technology opens the possibility of joining materials difficult to weld by traditional fusion processes, such as $\mathrm{Mg} /$ Steel [4], $\mathrm{Al} / \mathrm{Ti}$ [5], $\mathrm{Al} / \mathrm{Mg}$ [6], and $\mathrm{Al} / \mathrm{Cu}$ [7] combinations. However, industrial joining between such dissimilar materials still remains a technological challenge because of the numerous parameters which could affect the joint quality.

Numerous studies concerning FSW were performed focusing on different aspects of the process: tool material [8], tool shoulder geometry [9], pin global geometry [10] and thread [11], material flow, and heat generated during the welding $[12,13]$. The joint has been analyzed by residual stress measurements [14] and microstructure characterization [15]. Moreover, it is well known that FSW results in the formation of layers of InterMetallic Compounds (IMC) through the interface. The covalent 
bonds in IMC increase the binding energy and decrease the number of available free electrons, generally increasing the brittleness of the junction [16]. However, for an optimal thickness, intermetallics provide good bonding characteristics as long as the layer remains compact. Previous studies therefore aim to determine the existence of an optimal intermetallic layer thickness as far as the mechanical properties are concerned [17].

Stainless steel 316L and aluminum alloys 5083 are often used in the transport industry but welding them together remains difficult. Some previous studies concerning this combination focused on the microstructure evolution $[18,19]$ in different joining configurations. In butt joining configuration, some investigations dealt with the relation between mechanical strength and the existence of stainless steel particles in aluminum [20] or on IMC growth following the main process parameters [18]. Methods using the Taguchi technique extract the influence on the welding quality for each processing parameter [21]. In lap join configuration, probe penetration in the lower part influences the welding quality [22]. The mechanical strength of the joint drastically decreases if the probe does not penetrate the lower level of the lap configuration. On the probe path, the tool revolution speed and welding speed affect the grain size reduction and the mechanical strength [15]. From a metallurgical point of view, aluminum-stainless steel FSW method mainly creates $\mathrm{FeAl}_{3}$ intermetallic compound which can decrease the mechanical strength of the junction [23] for a critical IMC thickness higher than $20 \mu \mathrm{m}$ typically [24].

The main objective of this work is to present a methodology of FSW using a lap join configuration developed to weld a stainless steel 316L-aluminum alloy 5083 combination and the way to optimize the mechanical strength of the junction. To this end, the link between the mechanical strength of the weld and the IMC thickness induced by the process heat input was investigated. It was demonstrated that an optimal thickness can be reached by an adequate choice of process parameters.

\section{Materials and Methods}

For this study, a FSW configuration (Sominex, Bayeux, France) is used, inspired from Kimapong and Watanabe [24]. In such a configuration, a 5083 aluminum sheet (4.85 $\mathrm{mm}$ in thickness) covers a 316L stainless steel sample (3.5 $\mathrm{mm}$ in thickness). Chemical composition of the alloys is given in Table 1.

The tool in Figure 1a entirely goes through the aluminum alloy and scratches the surface of the stainless steel. The depth penetration inside the stainless steel is held at $0.35 \mathrm{~mm}$. On the welding zone, the aluminum alloy sheet is entirely stirred by the pin with a $3^{\circ}$ tilt (Figure $\left.1 b, c\right)$. The tool is made of tungsten carbide and has a $12 \mathrm{~mm}$ diameter flat shoulder. The probe has a threaded conical shape and is about $5 \mathrm{~mm}$ in length. The end of the pin has a $4 \mathrm{~mm}$ diameter corresponding to the width of the welded zone.

Table 1. Chemical composition (wt. \%) of aluminum 5083 and stainless steel 316L alloys.

\begin{tabular}{cccccccc}
\hline \multicolumn{7}{c}{ Aluminum 5083 (Al Balance) } \\
\hline $\mathrm{Mg}$ & $\mathrm{Si}$ & $\mathrm{Fe}$ & $\mathrm{Cu}$ & $\mathrm{Mn}$ & $\mathrm{Cr}$ & $\mathrm{Zn}$ & $\mathrm{Ti}$ \\
$4.0-4.9$ & 0.40 & 0.40 & 0.10 & 0.25 & $0.05-0.25$ & 0.20 & 0.15 \\
\hline \multicolumn{7}{c}{ Stainless } & Steel 316L (Fe Balance) \\
\hline $\mathrm{C}$ & $\mathrm{Si}$ & $\mathrm{Mn}$ & $\mathrm{Cr}$ & $\mathrm{Ni}$ & $\mathrm{Mo}$ & - & - \\
0.025 & 0.40 & 1.20 & 16.80 & 10.10 & 2.10 & - & - \\
\hline
\end{tabular}




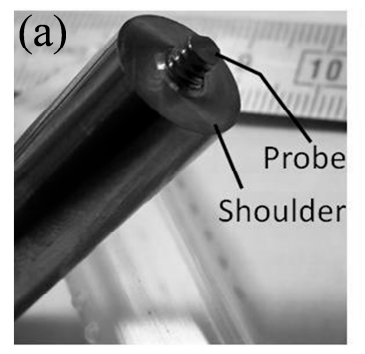

(b)

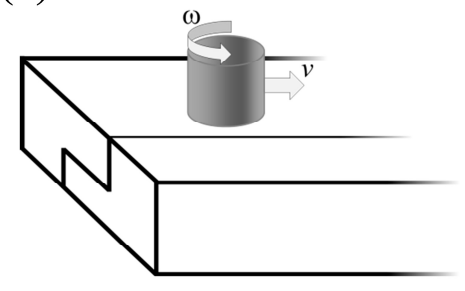

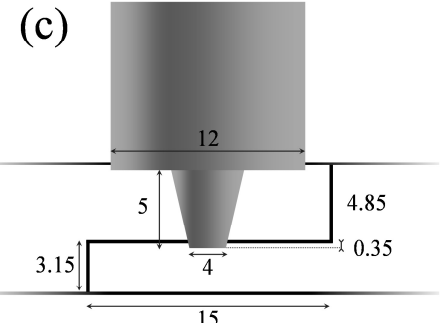

Figure 1. Friction stir welding setup. (a) FSW tool used for all the samples. (b) Schematic representation of the tool in the lap joining configuration and tool parameters. (c) Lap join friction stir welding cross section (dimensions in $\mathrm{mm}$ ).

During the welding, local warming of the zone can take place, mainly generated by friction between metal and shoulder. The temperature locally reaches 0.6 to 0.75 times the melting point of aluminum alloy [1]. In addition, the rotational movement of the tool produces a flow of material from the front to the back of the pin which plastically deforms and compresses the material around the shoulder. This phenomenon induces important microstructural changes [25]. Two process parameters were studied [26]: the rotational speed $\omega$ of the tool, ranging from $600 \mathrm{rpm}$ to $2100 \mathrm{rpm}$, and the welding speed $v$ in the $10-100 \mathrm{~mm} \cdot \mathrm{min}^{-1}$ range. The two parameters were studied from a Taguchi ANOVA DoE (Design of Experiment) plan with a $\mathrm{L}_{16}$ resolution in order to localize the optimal region of the process parameters [27]. A model based on dimensional analysis, developed by Roy et al. [28], was used to estimate a non-dimensional heat input $Q^{*}$ during welding, which is expressed by Equation (1). Since the coefficient of friction changes with temperature, it is difficult to accurately calculate the corresponding heat generation. This parameter strongly depends on the ratio $f$ between thermal properties of the materials at the tool/aluminum alloy interface (Equation (2)).

$$
Q^{*}=\frac{f \sigma_{Y 80} A \omega C_{P}}{k v^{2}},
$$

with:

$$
f=\left(\frac{k^{A l} \rho^{A l} C_{P}^{A l}}{k^{T} \rho^{T} C_{P}^{T}}\right)^{1 / 2}=0.971,
$$

$k$ represents the thermal conductivity, $\rho$ is the density and $C_{P}$ is the specific heat. $\sigma_{Y 80}$ is the yield stress of the upper material (aluminum alloy) at $80 \%$ of the solidus temperature and $A=10^{-4} \mathrm{~m}^{2}$ is the cross-section area of the tool. The combination between the translation speed $v$ of the tool and its rotational velocity $\omega$ enables to calculate $Q^{*}$ which ranges from 0.20 to 64 in this study. Input constant values are listed in Table 2.

Table 2. Input constants of aluminum [29] and WC tool [30] for $Q^{*}$ computation.

\begin{tabular}{ccccccc}
\hline \multicolumn{3}{c}{ Aluminum } & \multicolumn{3}{c}{ Tool } \\
\hline$k^{A l}$ & $\rho^{A l}$ & $C_{P}{ }^{A l}$ & $\sigma_{\gamma 80}$ & $k^{T}$ & $\rho^{T}$ & $C_{P}^{T}$ \\
$\left(\mathrm{~W} \cdot \mathrm{m}^{-1} \cdot \mathrm{K}^{-1}\right)$ & $\left(\mathrm{g} \cdot \mathrm{cm}^{-3}\right)$ & $\left(\mathrm{J} \cdot \mathrm{K}^{-1} \cdot \mathrm{kg}^{-1}\right)$ & $(\mathrm{MPa})$ & $\left(\mathrm{W} \cdot \mathrm{m}^{-1} \cdot \mathrm{K}^{-1}\right)$ & $\left(\mathrm{g} \cdot \mathrm{cm}^{-3}\right)$ & $\left(\mathrm{J} \cdot \mathrm{K}^{-1} \cdot \mathrm{kg}^{-1}\right)$ \\
117 & 2.66 & 900 & 7.5 & 110 & 13.30 & 203 \\
\hline
\end{tabular}

Tensile samples were cut perpendicular to the welding direction as in Figure 2 in order to obtain the ultimate shear strength (USS) $\tau_{\max }$ supported by the weld. Samples were tested on a 5569 dual column machine (INSTRON, Norwood, MA, USA) with a constant displacement of $1 \mathrm{~mm} \cdot \mathrm{min}^{-1}$. Monotonous tensile tests were performed using traditional ASTM standards on $20 \mathrm{~mm}$ junction length samples from a $200 \mathrm{~mm}$ length of plates. The junction was positioned in the middle of the $55 \mathrm{~mm}$ in the tensile machine jaws space. For each $Q^{*}$ value, at least three tensile tests were performed in order to take into account the dispersion of the results. The welded junction is parallel to the tensile direction 
and the surface $S$ which supports the shear strength is the welding bead length (about $20 \mathrm{~mm}$ ) of the sample by the probe width $(4 \mathrm{~mm}) \cdot \tau_{\max }$ is obtained by the ratio between the maximal strength $F_{\max }$ and the surface $S$.

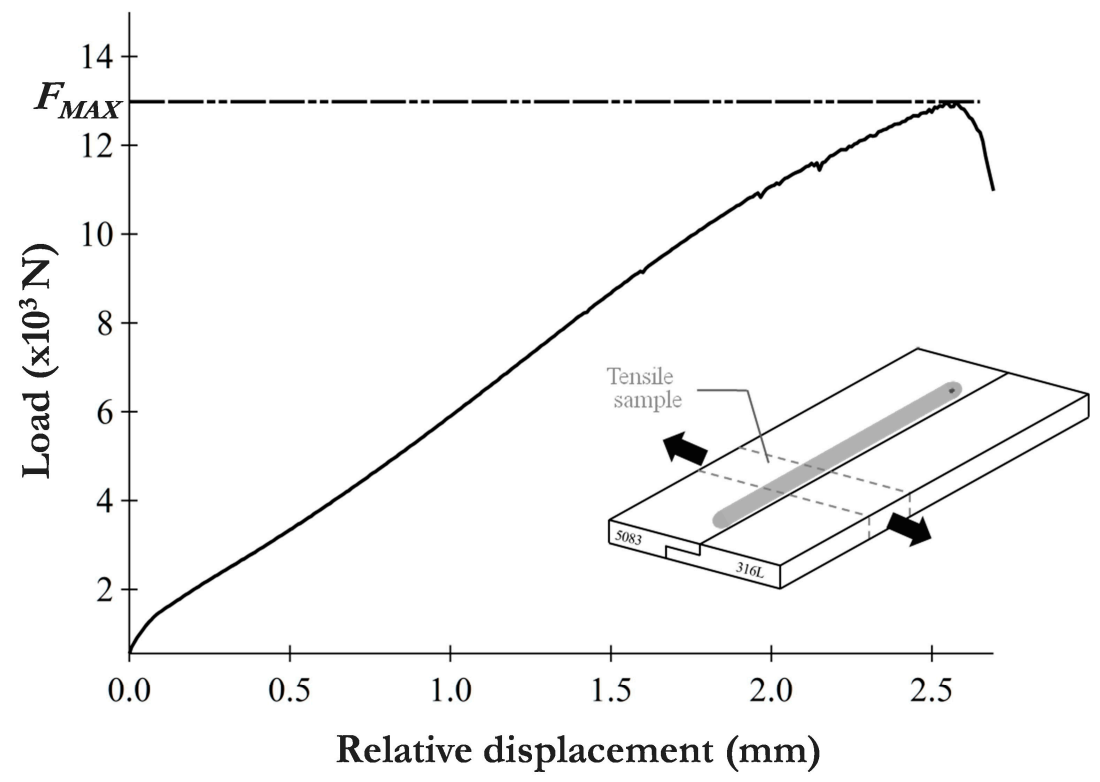

Figure 2. Typical mechanical test curve $\left(Q^{*}=48\right)$. In inset: Sample cutting pattern on a weld bead.

Microscopic observations of the interface were carried out by Scanning Electron Microscopy (SEM ZEISS SUPRA 55 EDS, Marly le Roi, France). The analysis of composition was performed by Energy Dispersive Spectrometry (EDS) on mechanical polished specimens. Complementary phase identification was carried out using X-ray diffractometer (Bruker, Conventry, UK) with monochromatic $\mathrm{Cu} \mathrm{K} \mathrm{K}_{\alpha}$ radiation and continuous scan mode at $0.25^{\circ} / \mathrm{min}$ over a wide angle range of $30-90^{\circ}$. Transmission Electron Microscopy (TEM) (JEOL 2010, Croissy-sur-Seine, France) operating at 200 kV enables microstructural observations with dark field imaging and IMC identification with diffraction patterns and additional local EDS measurements. Thin foils for TEM observations were prepared in cross sectional configuration at the interface by Focused Ion Beam (FIB) method. This was performed with a dual beam FEI 660 (Nanolab Inc., Waltham, MA, USA) operating with Ga+ ions at $30 \mathrm{keV}$.

\section{Experimental Results}

Figure 3 shows typical cross sections perpendicular to the welding path of the junction for increasing values of $Q^{*}$. The path of the pin is clearly visible at the interface between the stainless steel (light grey) and the aluminum alloy (dark grey). For some values of $Q^{*}$, two long intrusions of stainless steel can be observed around the part, inside the aluminum part (Figure 3c). These metal shapes are not necessarily symmetric and were already mentioned between two aluminum sheets as Cold Lap Defects (CLD) [31]. The biggest CLD is mostly at the retreating side and generates an additional strength which contributes to the resistance of the weld. When the depth penetration of the tool increases, the CLDs are larger. However, for lower values of $Q^{*}$, as it can be seen in Figure $3 b$, these defects appear to be unstable, crushed in small parts and dispersed in the aluminum alloy.

In addition, microstructural observations of the interface also exhibit the presence of ultra-fine intermetallic compounds in the form of discontinuous thin shapes in stainless steel, especially visible in Figure 3a,d. This can be attributed to the presence of intermetallic compounds as it was already mentioned by Kimapong and Watanabe [24] for A5083 aluminum-SS400 steel couple. When the heat coefficient $Q^{*}$ is higher than 45 , the IMCs grow faster and interface appears as a multilayer composed of stainless steel 316L matrix and rich-(FeAl) IMCs (Figure 4). The thermal expansion coefficient between stainless steel $\left(\alpha_{S S}=16-18 \mu \mathrm{m} \cdot \mathrm{m}^{-1} \cdot \mathrm{K}^{-1}\right)$, aluminum $\left(\alpha_{A l}=23.4 \mu \mathrm{m} \cdot \mathrm{m}^{-1} \cdot \mathrm{K}^{-1}\right)$ and IMC 
$\left(\alpha_{\mathrm{FeAl3}}=14 \mu \mathrm{m} \cdot \mathrm{m}^{-1} \cdot \mathrm{K}^{-1}\right)$ [32] vary in a wide range and create high residual stresses which induce cracks all along the interface after the cooling of the samples. Depending on $Q^{*}$, the intermetallic compound grows first perpendicular to the interface and either continues in the same direction, or changes direction to grow parallel to the 5083/316L interface. This results are in good agreement with previous observations [33].
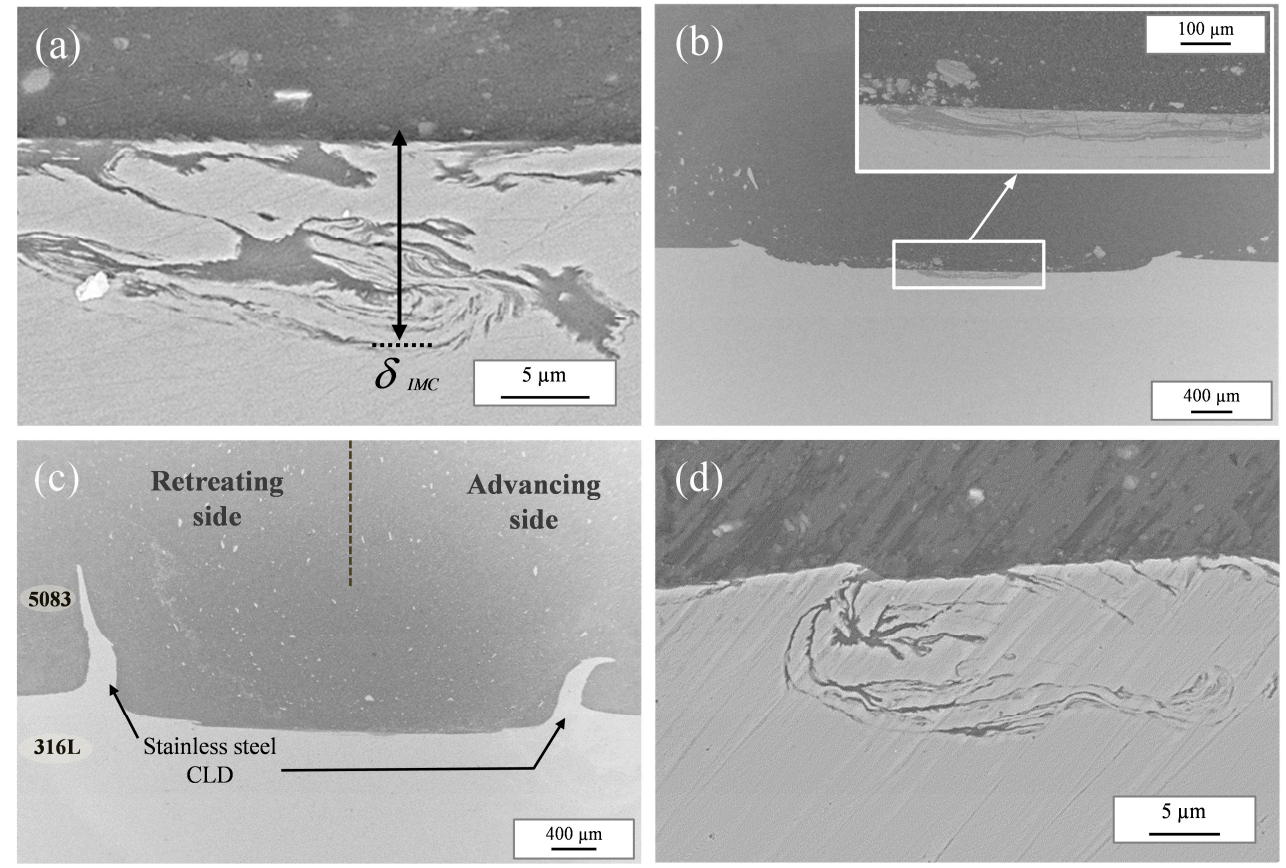

Figure 3. Cross section and InterMetallic Compound (IMC) protrusion at the welded interface for increasing values of $Q^{*}$. (a) Examples of measurement of the characteristic depth of IMC $\delta_{I M C}$. $\left(Q^{*}=0.39\right)$. (b) Stainless steel fragmentation around the welded interface at low heat input $\left(Q^{*}=2.5\right)$.

(c) Cross section observation of welded interface and Cold Lap Defects (CLD) highlights $\left(Q^{*}=56.4\right)$.

(d) IMC infiltration profile at higher $Q^{*}$ values $\left(Q^{*}=64.1\right)$.
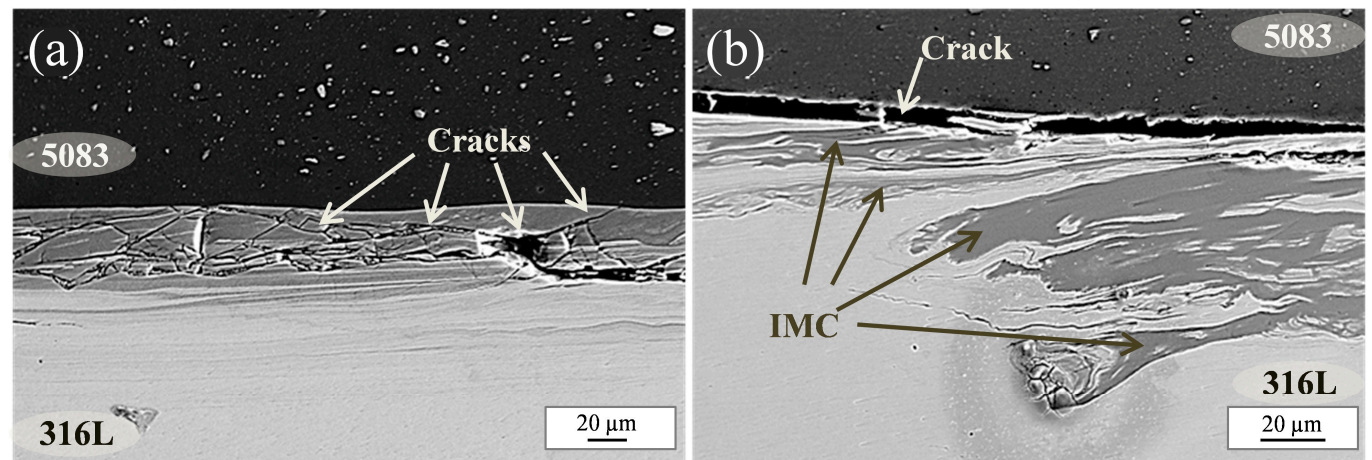

Figure 4. Scanning Electron Microscopy (SEM) interface observation for high values of $Q^{*}$. (a) Broken IMC at the interface $Q^{*}=48.01,(\mathbf{b})$ crack along the interface $Q^{*}=56.4$.

In order to identify the nature of the IMC, EDS was performed on several zones rich in intermetallics. Chemical analyses reveal the presence of an Al-rich IMC of $\mathrm{FeAl}_{3}$ nominal composition as evidenced in Figure $5 \mathrm{a}, \mathrm{b}$. However, the binary phase diagram $\mathrm{Fe} / \mathrm{Al}$ contains five different intermetallic compounds [34]. Others studies by Girard et al. [35] and Nishida et al. [23] pointed out that not all intermetallics predicted by equilibrium phase diagram are present after stir welding process, the principal IMC in both studies being $\mathrm{FeAl}_{3}\left(\mathrm{Fe}_{4} \mathrm{Al}_{13}\right)$. This could be explained by the 
fact that FSW is a complex process of plastic deformation and heating, far from the equilibrium thermodynamic conditions.

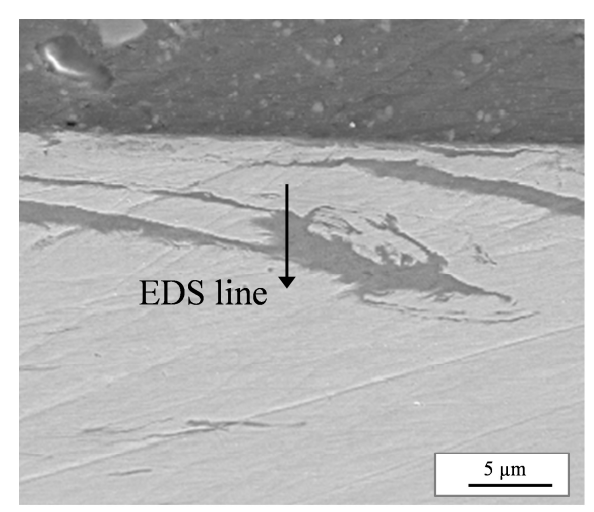

(a)

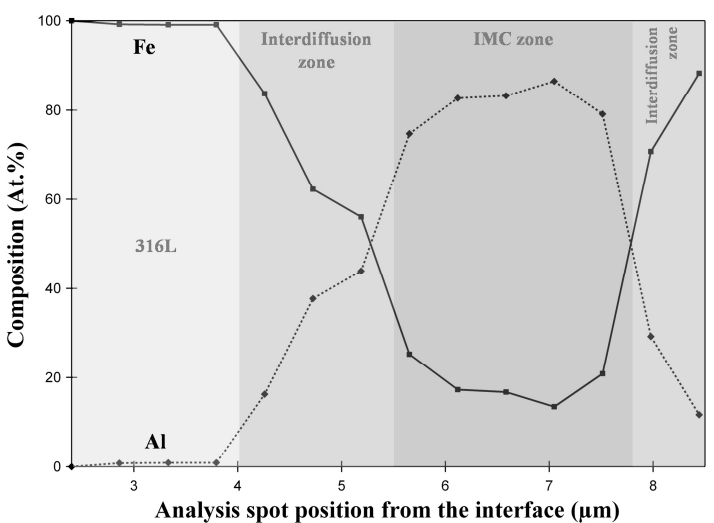

(b)

Figure 5. Identification of the intermetallic compound by Energy Dispersive Spectrometry (EDS). (a) EDS measurement line through the IMC zone at the welded interface $\left(Q^{*}=0.86\right)$. (b) Atomic composition along the EDS line.

XRD measurements (Figure 6) confirm the existence of $\mathrm{FeAl}_{3}$ but also exhibit traces of $\mathrm{Fe}_{2} \mathrm{Al}_{5}$. This second IMC was not identified for all process conditions and can be related to specific values of $Q^{*}$. Deeper insight into the IMC layer at the interface is provided by TEM. The principal results are included in Figure 7. The bottom of the figure represents a reconstructed view of the thin lamella. The initial materials can be readily identified. The aluminum alloy (in the right part of the picture) is composed of grains of uniform size (around $3 \mu \mathrm{m}$ ), one of the representative diffraction pattern of the cubic structure of aluminum is shown (grey arrow). The aluminum side contains also iron rich particles. Such particles could pre-exist in the parent $\mathrm{Al}$ material but also are probably pieces of steels torn off during the welding process that were afterwards enriched in aluminum by diffusion.

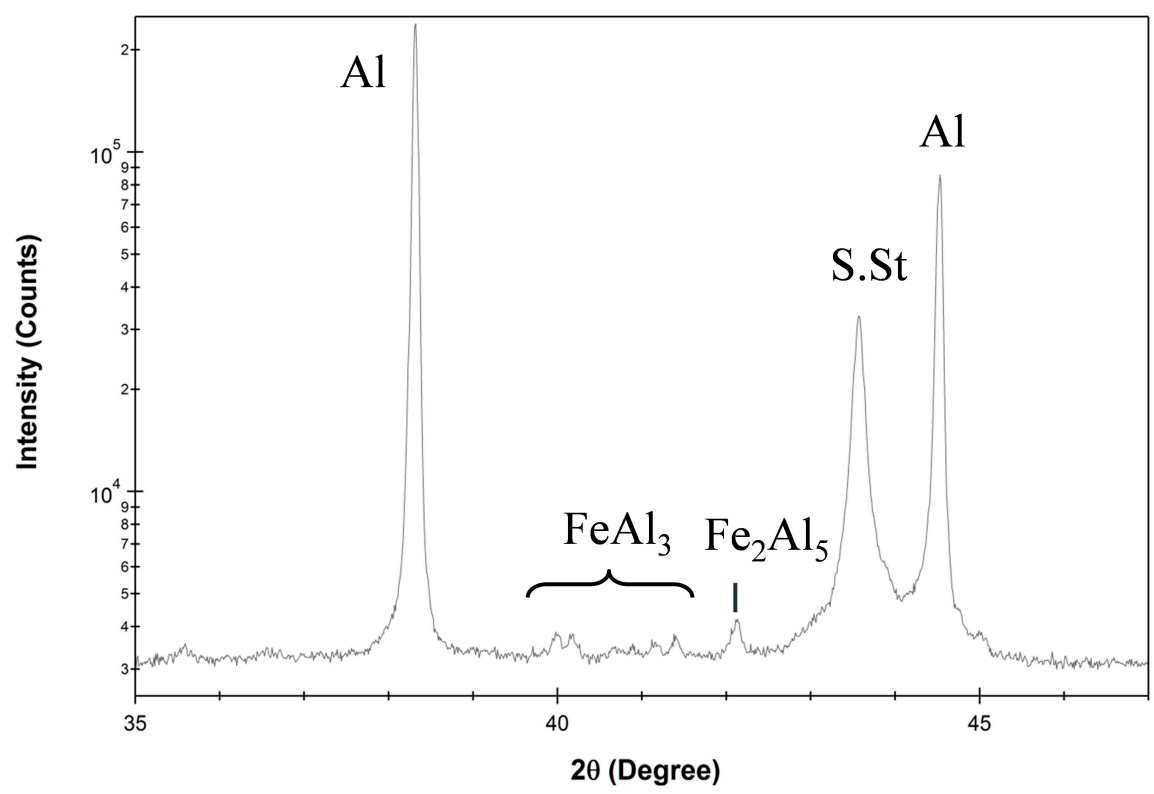

Figure 6. XRD spectra analysis focusing on typical Fe-Al IMC peaks in the range of $35-47^{\circ}$ (S.St. is the abbreviation of Stainless Steel). 

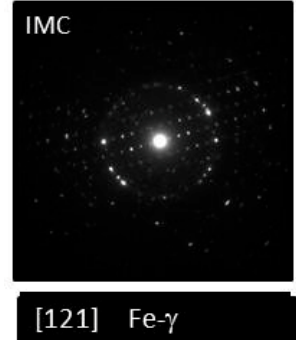

$\sqrt{10}$

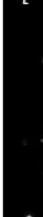

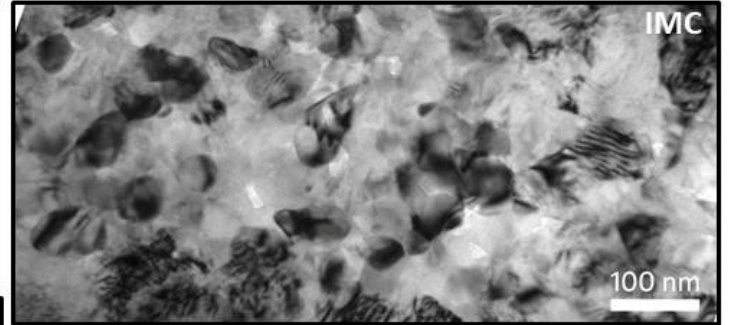

$$
\text { composition in wt. \% }
$$

IMC

$$
69 \% \mathrm{Al}
$$

$26 \% \mathrm{Fe}$

$5 \% \mathrm{Cr}$
Iron rich particle

$69 \% \mathrm{Fe}$

$26 \% \mathrm{Al}$

$18 \% \mathrm{Mn}$

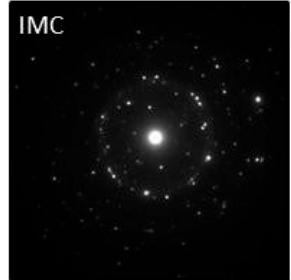

[100] Al

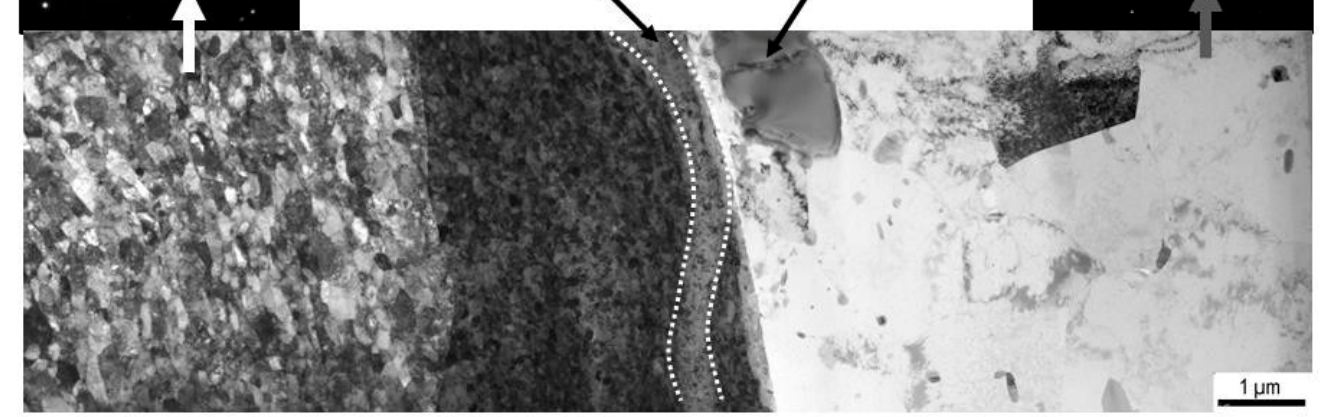

Figure 7. Identification of the intermetallic compounds by Transmission Electron Microscopy (TEM) showing the presence of traces of $\mathrm{Fe}_{2} \mathrm{Al}_{5}$ and $\mathrm{FeAl}_{2}$.

The stainless steel, at the left part of the image, exhibits submicron-sized grains, the size of which decreases when approaching the interface. The electron diffraction analysis was performed at around $6 \mu \mathrm{m}$ from the interface where grains can be easily selected for identification (white arrow). It turns clear that the process affects the initial microstructure of steel producing nanostructured grains near the interface in the $0.35 \mathrm{~mm}$ thick strip of material.

Another clearly identifiable zone is highlighted with dotted lines along the interface. This zone of a wavy shape can be associated with the IMC. The microstructure of IMC is shown in the top image of Figure 7 together with representative selected area electron diffraction (SAED) patterns. The identification of this nanostructured intermetallic was not possible. Diffraction patterns were in all tested cases a complex mixture of diffraction of grains with different orientations.

EDS analysis of the IMC zone seems to confirm that there is the presence of the $\mathrm{FeAl}_{3}$ and/or $\mathrm{Fe}_{2} \mathrm{Al}_{5}$ compounds. However, due to their relatively close stoichiometric ratios, the nanometer size of grains and to the fact that the analysis is rather semi-quantitative, it is difficult to distinguish reliably the two compounds.

The highly disturbed character of the interface makes it difficult to analyze the different phases. In addition, it is known that $\mathrm{FeAl}_{3}$ first grows and then decreases due to the formation of $\mathrm{Fe}_{2} \mathrm{Al}_{5}$ upon traditional welding [36]. Finally, it is also noticeable that the different compositions highlighted by EDS could reveal the existence of a more complex rich-FeAl $\mathrm{IMC}_{3}$, enriched in chromium, originating from the initial composition of the stainless steel. Indeed, FSW process enables a fast atomic diffusion through the interface allowing the nucleation and growth of intermediate phases.

All of these results allow concluding that upon the FSW process there are many phenomena that occur (mechanical and thermal) at the interface, which allow the formation of highly mixed zone, comprising of different IMC compounds such as $\mathrm{FeAl}_{3}$ and $\mathrm{Fe}_{2} \mathrm{Al}_{5}$.

In order to quantify the mechanical resistance of the weld, USS values of the most relevant tests are given in Table 3 in function of $Q^{*}$. 
Table 3. Average value of the maximum shear strength $\tau_{\max }$ for various values of $Q^{*}$.

\begin{tabular}{cccccccccc}
\hline$Q^{*}$ & $\mathbf{0 . 2 1}$ & $\mathbf{0 . 3 9}$ & $\mathbf{0 . 8 6}$ & $\mathbf{2 . 5 2}$ & $\mathbf{3 . 3 7}$ & $\mathbf{4 8 . 0 1}$ & $\mathbf{2 3 . 9 4}$ & $\mathbf{5 6 . 3 6}$ & $\mathbf{6 4 . 1 1}$ \\
\hline$\tau_{\max }(\mathrm{MPa})$ & $95 \pm 20$ & $127 \pm 12$ & $106 \pm 25$ & $130 \pm 12$ & $92 \pm 7$ & $83 \pm 3$ & $70 \pm 4$ & $62 \pm 15$ & $124 \pm 4$ \\
\hline
\end{tabular}

The heat process strongly influences the mechanical resistance of the junction for the Stainless Steel-Al alloy combination in contrast to others combinations as for instance the Al-Ti system [37]. Even for the lowest value of $Q^{*}\left(Q^{*}=0.21\right)$, the joint exhibits a broad range of shear strength values between 85-105 MPa. $\tau_{\max }$ sensitively increases with $Q^{*}$ until reaching an optimum around $130 \mathrm{MPa}$ for $Q^{*}=2.52$ (the error bars also decrease here). For higher values of $Q^{*}, \tau_{\max }$ decreases down to $62 \mathrm{MPa}$ for $Q^{*}=56$. However, for greatest values of $Q^{*}$ (close to 64 ), $\tau_{\max }$ exhibits again high levels, around $125 \mathrm{MPa}$. This phenomenon is closely linked to the interface organization of intermetallic compounds, coupled with the existence of mechanical anchoring created from the tool path. The numerous cracks depicted along the interface for $Q^{*}$ higher than 60 imply therefore that the welds are not acceptable from an industrial point of view.

\section{Discussion-Correlation between Ultimate Shear Strength, Heat Input, and IMC Depth}

This part discusses in more details the different depths of the IMC zone, as a function of the different values of $Q^{*}$, and their influence on the mechanical resistance of the junction. Even if it is difficult to precisely identify the nature and a precise thickness of IMC phases at the interface of the junction, an IMC depth $\left(\delta_{I M C}\right)$, corresponding to the thickness affected by the presence of these IMCs can be estimated. An example showing an estimation of $\delta_{I M C}$ is given in Figure 3a. These $\delta_{I M C}$ values were measured for each value of $Q^{*}$, and represented in Figure 8a. Three distinct stages can be identified in this figure. In the first stage (low heat input $Q^{*}$ belongs to [0.2-2.5]), the thickness of stainless steel affected by IMCs remains almost constant with a $\delta_{I M C}$ value around $9 \mu \mathrm{m}$. This stage is representative of the nucleation of rich- $\mathrm{FeAl}_{3} \mathrm{IMCs}$ followed by its growth which appear relatively slow and controllable. This is the combination of the mechanical and thermal phenomenon from the welding process which allows IMCs emergence even at very low provided heat input. After a critical value $Q^{*}=2.5$, the second stage is related to a strong increase in $\delta_{I M C}$. During this stage, rich-FeAl extends and widens inside the volume of stainless steel leading to IMC percolation mechanisms. In the third stage, related to high values of $Q^{*}\left(Q^{*}>48\right)$, the IMC grows less in depth in the stainless steel and becomes more parallel to the interface, which implies a decrease of $\delta_{I M C}$. This last step represents a stage of overgrowth for rich-FeAl $\mathrm{IMCs}_{3}$. When higher values of $Q^{*}$ are reached (typically $\left.Q^{*}=64\right), \delta_{I M C} \approx 10 \mu \mathrm{m}$ which corresponds to the same order as values reached in the first stage. However, the shape of IMC layers is clearly different. In this stage, $\delta_{I M C}$ corresponds to a single layer originated from interdiffusion mechanisms. This can be theoretically described with the traditional Matano-Boltzmann approach for a two-phase system [38,39].

The mechanical resistance of the weld is represented by the USS value $\tau_{\max }$ obtained by shear lap tests. $\tau_{\max }$ is displayed as a function of $\delta_{I M C}$ in Figure $8 \mathrm{~b}$. It can be observed, an increase of $\tau_{\max }$ until an optimum value of around $130 \mathrm{MPa}$ for $\delta_{I M C}=15 \mu \mathrm{m}$. When $\delta_{I M C}$ is higher than $15 \mu \mathrm{m}, \tau_{\max }$ strongly decreases. It is noticeable that, as explained in the previous paragraph, for relatively close values of $\delta_{I M C}$, very different shapes of IMC layers can be depicted. From these results, it is thus clear that the ultimate shear stress of the weld can be related mainly to the thickness of the stainless steel affected by the rich- $\mathrm{FeAl}_{3} \mathrm{IMCs}$, as shown in Figure $8 \mathrm{~b}$ independently of their shapes. This curve highlights the existence of an optimal $\delta_{I M C} \approx 15 \mu \mathrm{m}$ giving the maximum mechanical resistance of the interface. For higher values of $\delta_{I M C}, \tau_{\max }$ decreases drastically and reaches a lower asymptote about $80 \mathrm{MPa}$ for $\delta_{I M C} \geq 50 \mu \mathrm{m}$. The increase in $\delta_{I M C}$ leads to non-cohesive and brittle IMC layers and the maximal shear strength therefore decreases. 

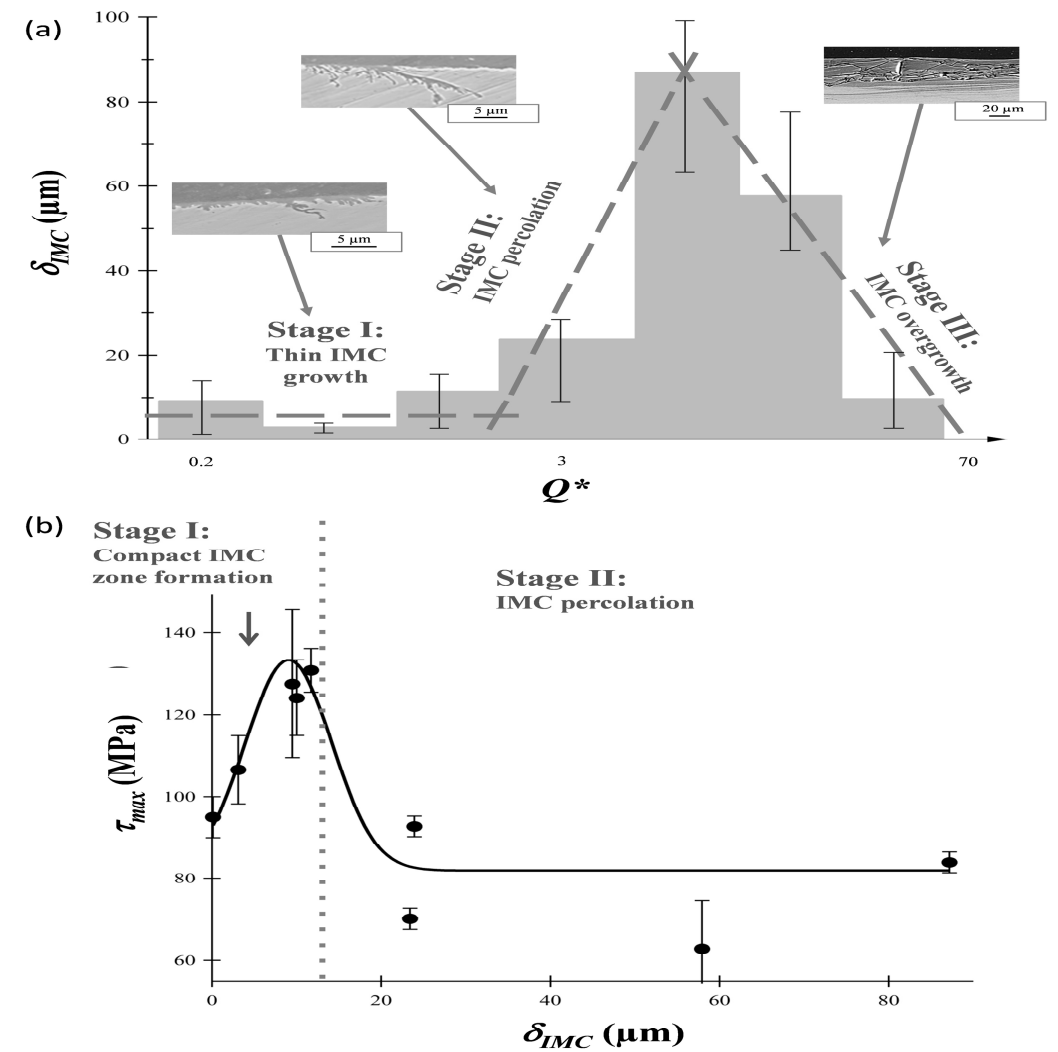

Figure 8. Correlation between $\tau_{\max }, Q^{*}$ and the IMC affected zone. (a) $\delta_{I M C}$ plotted against $Q^{*}$ (logarithmic scale for $Q^{*}$ ). (b) Maximum shear strength in function of $\delta_{I M C}$.

\section{Conclusions}

FSW process was conducted between a stainless steel 316L and an aluminum alloy 5083 in order to determine the optimum parameters giving the higher mechanical resistance of the weld. A lap joint configuration with a lower part penetration was used with the aluminum sheet covering the 316L sample. It was possible in this work to link the heat coefficient during the welding process to the ultimate shear stress and to the thickness of stainless steel affected by the existence of rich-Fe $\mathrm{Al}_{3} \mathrm{IMC}$. Main results of this research can be summarized as follows:

- Rich-FeAl $\mathrm{Al}_{3}$ compound was the only intermetallic detected along the weld interface independent of the FSW parameters.

- IMC growth mechanisms are linked to the heat input coefficient $Q^{*}$ with three distinct stages of formation which influence the mechanical behavior of the interface.

- For an optimal thickness of about $15 \mu \mathrm{m}$ inside the stainless steel, rich-FeAl $\mathrm{IMCs}_{3}$ are present under the form of thin compact layers ensuring a good chemical cohesion of the weld. High values of the mechanical resistance of the weld are reported (130 MPa of shear strength as optimum value) in these optimal conditions.

- For higher values of the IMC thickness, ultimate shear stress dramatically decreases up to a minimal value of $80 \mathrm{MPa}$ on average, and numerous cracks are depicted along the interface. The cohesion of the weld is only ensured by the existence of cold lap defects which act as mechanical anchors between the two samples.

Author Contributions: The paper is the result of a collaboration of all co-authors, Florent Picot performed this work during his Ph.D. Thesis, under the supervision of Eric Hug, Ph.D. director. Antoine Gueydan contributes to the study of experimental results, Mayerling Martinez and Florent Moisy performed TEM and XRD experiments.

Conflicts of Interest: The authors declare no conflict of interest. 


\section{References}

1. Thomas, W.M.; Threadgill, P.L.; Nicholas, E.D. Feasibility of friction stir welding steel. Sci. Technol. Weld. Join. 1999, 4, 365-372. [CrossRef]

2. Thomas, W.M.; Nicholas, E.D. Friction stir welding for the transportation industries. Mater. Des. 1997, 18, 269-273. [CrossRef]

3. Dey, H.C.; Ashfaq, M.; Bhaduri, A.K.; Rao, K.P. Joining of titanium to 3041 stainless steel by friction welding. J. Mater. Process. Technol. 2009, 209, 5862-5870. [CrossRef]

4. Kasai, H.; Morisada, Y.; Fujii, H. Dissimilar fsw of immiscible materials: Steel/magnesium. Mater. Sci. Eng. A 2015, 624, 250-255. [CrossRef]

5. Chen, Y.; Liu, C.; Liu, G. Study on the joining of titanium and aluminum dissimilar alloys by friction stir welding. Open Mater. Sci. J. 2011, 5, 256-261. [CrossRef]

6. Pourahmad, P.; Abbasi, M. Materials flow and phase transformation in friction stir welding of al 6013/mg. Trans. Nonferrous Met. Soc. China 2013, 23, 1253-1261. [CrossRef]

7. Xue, P.; Xiao, B.L.; Ni, D.R.; Ma, Z.Y. Enhanced mechanical properties of friction stir welded dissimilar Al-Cu joint by intermetallic compounds. Mater. Sci. Eng. A 2010, 527, 5723-5727. [CrossRef]

8. Rai, R.D.; Bhadeshia, H.K.D.H.; DebRoy, T. Friction stir welding tools. Sci. Technol. Weld. Join. 2011, 16, 325-342. [CrossRef]

9. Li, D.; Yang, X.; Cui, L.; He, F.; Zhang, X. Investigation of stationary shoulder friction stir welding of aluminum alloy 7075-t651. J. Mater. Process. Technol. 2015, 219, 112-123. [CrossRef]

10. Mishra, R.S.; Ma, Z.Y. Friction stir welding and processing. Mater. Sci. Eng. R 2005, 50, 1-78. [CrossRef]

11. Lin, Y.C.; Chen, J.N. Influence of process parameters on friction stir spot welded aluminum joints by various threaded tools. J. Mater. Process. Technol. 2015, 225, 347-356. [CrossRef]

12. Mohanty, H.K.; Venkateswarlu, D.; Mahapatra, M.M.; Kumar, P.; Mandal, N.R. Modeling the effects of tool probe geometries and process parameters on friction stirred aluminium welds. J. Mech. Eng. Autom. 2012, 2, 74-79. [CrossRef]

13. Reynolds, A.P. Visualisation of material flow in autogenous friction stir welds. Sci. Technol. Weld. Join. 2000, 5, 120-124. [CrossRef]

14. Zapata, J.; Toro, M.; Lopez, D. Residual stresses in friction stir dissimilar welding of aluminum alloys. J. Mater. Process. Technol. 2016, 229, 121-127. [CrossRef]

15. Bisadi, H.; Tour, M.; Tavakoli, A. The influence of process parameters on microstructure and mechanical properties of friction stir welded al 5083 alloy lap joint. Am. J. Mater. Sci. 2011, 1, 93-97. [CrossRef]

16. Hug, E.; Bellido, N. Brittleness study of intermetallic $(\mathrm{Cu}, \mathrm{Al})$ layers in copper clad aluminium thin wires. Mater. Sci. Eng. A 2011, A528, 7103-7106. [CrossRef]

17. Kimapong, K.; Watanabe, T. Effect of welding process parameters on mechanical property of fsw lap joint between aluminum alloy and steel. Mater. Trans. 2005, 46, 2211-2217. [CrossRef]

18. Lan, S.; Liu, X.; Ni, J. Microstructural evolution during friction stir welding of dissimilar aluminum alloy to advanced high-strength steel. Int. J. Adv. Manuf. Technol. 2016, 82, 2183-2193. [CrossRef]

19. Yazdipour, A.; Heidarzadeh, A. Effect of friction stir welding on microstructure and mechanical properties of dissimilar al 5083-h321 and 3161 stainless steel alloys joints. J. Alloys Compd. 2016, 680, 595-603. [CrossRef]

20. Yazdipour, A.; Heidarzadeh, A. Dissimilar butt friction stir welding of al 5083-h321 and 3161 stainless steel alloys. Int. J. Adv. Manuf. Technol. 2016, 87, 3105-3112. [CrossRef]

21. Chen, T. Process parameters study on fsw joint of dissimilar metals for aluminum-steel. J. Mater. Sci. 2009, 44, 2573-2580. [CrossRef]

22. Elrefaey, A.; Gouda, M.; Takahashi, M.; Ikeuchi, K. Characterization of aluminum/steel lap joint by friction stir welding. J. Mater. Eng. Perform. 2005, 14, 10-17. [CrossRef]

23. Nishida, T.; Ogura, T.; Nishida, H.; Fujimoto, M.; Takahashi, M.; Hirose, A. Formation of interfacial microstructure in a friction stir welded lap joint between aluminium alloy and stainless steel. Sci. Technol. Weld. Join. 2014, 19, 609-616. [CrossRef]

24. Kimapong, K.; Watanabe, T. Friction stir welding of aluminum alloy to steel. Weld. J. 2004, 83, $277-282$.

25. Threadgill, P.L.; Leonard, A.J.; Shercliff, H.R.; Withers, P.J. Friction stir welding of aluminium alloys. Int. Mater. Rev. 2009, 54, 49-93. [CrossRef]

26. Çam, G. Friction stir welded structural materials: Beyond al-alloys. Int. Mater. Rev. 2011, 56, 1-48. [CrossRef] 
27. De Filippis, L.; Serio, L.; Palumbo, D.; De Finis, R.; Galietti, U. Optimization and characterization of the friction stir welded sheets of aa 5754-h111: Monitoring of the quality of joints with thermographic techniques. Materials 2017, 10, 1165. [CrossRef] [PubMed]

28. Roy, G.G.; Nandan, R.; DebRoy, T. Dimensionless correlation to estimate peak temperature during friction stir welding. Sci. Technol. Weld. Join. 2006, 11, 606-608. [CrossRef]

29. Summers, P.T.; Chen, Y.; Rippe, C.M.; Allen, B.; Mouritz, A.P.; Case, S.W.; Lattimer, B.Y. Overview of aluminum alloy mechanical properties during and after fires. Fire Sci. Rev. 2015, 4, 1-36. [CrossRef]

30. Liu, K.; Li, X.P.; Rahman, M.; Liu, X.D. Cbn tool wear in ductile cutting of tungsten carbide. Wear 2003, 255, 1344-1351. [CrossRef]

31. Liu, H.; Hu, Y.; Peng, Y.; Dou, C.; Wang, Z. The effect of interface defect on mechanical properties and its formation mechanism in friction stir lap welded joints of aluminum alloys. J. Mater. Process. Technol. 2016, 238, 244-254. [CrossRef]

32. Masahashi, N.; Watanabe, S.; Nomura, N.; Semboshi, S.; Hanada, S. Laminates based on an iron aluminide intermetallic alloy and a crmo steel. Intermetallics 2005, 13, 717-726. [CrossRef]

33. Watanabe, M.; Feng, K.; Nakamura, Y.; Kumai, S. Growth manner of intermetallic compound layer produced at welding interface of friction stir spot welded aluminum/steel lap joint. Mater. Trans. 2011, 52, 953-959. [CrossRef]

34. Massalski, T.B.; Okamoto, H. Binary Alloy Phase Diagrams; ASM International Publishers: Materials Park, $\mathrm{OH}, \mathrm{USA}, 1990$.

35. Girard, M.; Huneau, B.; Genevois, C.; Sauvage, X.; Racineux, G. Friction stir diffusion bonding of dissimilar metals. Sci. Technol. Weld. Join. 2010, 15, 661-665. [CrossRef]

36. Movahedi, M.; Kokabi, A.H.; Reihani, S.M.S.; Najafi, H.; Farzadfar, S.A.; Cheng, W.J.; Wang, C.J. Growth kinetics of Al-Fe intermetallic compounds during annealing treatment of friction stir lap welds. Mater. Charact. 2014, 90, 121-126. [CrossRef]

37. Picot, F.; Gueydan, A.; Hug, E. Influence of friction stir welding parameters on titanium-aluminum heterogeneous lap joining configuration. AIP Conf. Proc. 2017, 1896, 050008.

38. Gueydan, A.; Domengès, B.; Hug, E. Study of the intermetallic growth in copper-clad aluminum wires after thermal aging. Intermetallics 2014, 50, 34-42. [CrossRef]

39. Kidson, G. Some aspects of the growth of diffusion layers in binary systems. J. Nucl. Mater. 1961, 3, $21-29$. [CrossRef] 